\title{
First Step towards Liquid State Electronics through Analysis of Liquid Resistivity in Water and Serum using different Electrodes
}

\author{
Manthan S. Manavadaria ${ }^{1}$, Vishal P. Tank ${ }^{2}$, Shivansh Dave ${ }^{3}$ \\ $\&$ Paras Mangukiya ${ }^{4}$ \\ ${ }^{1}$ Research Scholar, Electronics \& Communication Department, CSPIT-Changa, Gujarat, India, \\ ${ }^{2}$ Assistant Professor, Electronics \& Communication Department, CSPIT-Changa, Gujarat, India, IEEE Member \\ ${ }^{3}$ Student, Electronics \& Communication Department, CSPIT-Changa, Gujarat, India, \\ ${ }^{4}$ Student, Electronics \& Communication Department, CSPIT-Changa, Gujarat, India,
}

Abstract: Now days, the knowledge of the physical properties of liquid is always of high scientism and practical point of view. In this research paper electrical resistivity of a liquid has been taken as an important property and find out same for two liquids one for serum and second for water. Also the effect of Copper and Graphite electrode for both the liquids has been highlighted. The four followings experimental findings are compared 1) Copper Electrode-Water Liquid 2) Graphite Electrode-Water Liquid 3) Copper Electrode-serum Liquid 4) Graphite Electrode-Serum liquid.

This resistivity fact will provide the important data base in the field of bio-electronics.

Key Words: Liquid State Electronics, Bio Electronics, Resistance, Blood Plasma, Water, Copper \& Graphite

\section{Introduction}

The electrical resistance of an electrical conductor is the opposition to the passage of an electric current through that conductor. The SI unit of electrical resistance is the ohm $(\Omega)$. The current flowing through a wire (or resistor) is like water flowing through a pipe, resistance is proportional to how much pressure is required to achieve a given flow.

Ohm's law is an empirical law relating the voltage $\mathrm{V}$ across an element to the current $\mathrm{I}$ through

$$
V=I R
$$

The resistance of a given object depends primarily on two factors: What material it is made of, and its shape. For a given material, the resistance is inversely proportional to the cross-sectional area; for example, a thick copper wire has lower resistance than an otherwise-identical thin copper wire. Also, for a given material, the resistance is proportional to the length; for example, a long copper wire has higher resistance than an otherwise-identical short copper wire. The resistance can be computed as

$$
R=\rho \frac{l}{a}
$$

\section{Method Of Experiment}

For this experiment the general method of finding resistance of electrical components has been used. As shown in figure 1 initially liquid (serum or water) has taken in a bicker and circuit has connected on the table.

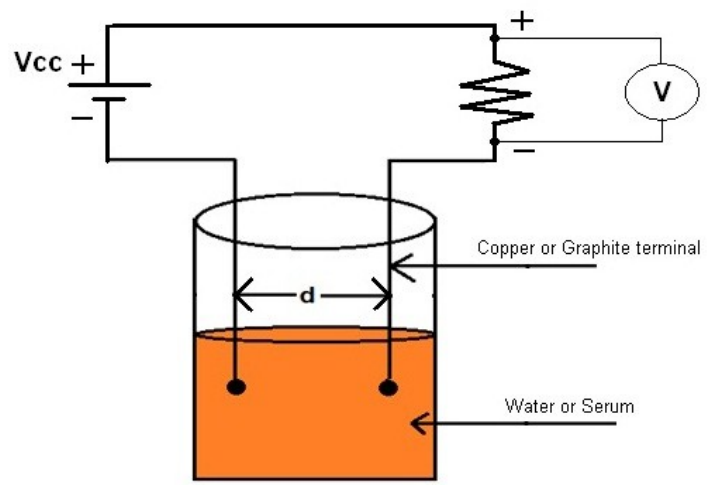

Fig. 1. Method of Experiment 
Initially experimental facts are taken as Table 1 . Necessary voltage has been applied and output has been measured. Alternatively four combinations have been used as following:

(1). Copper Electrode-Water Liquid

(2). Graphite Electrode-Water Liquid

(3). Copper Electrode-serum Liquid

(4). Graphite Electrode-Serum

Table 1 Experimental Facts At The Time Of Experiments

\begin{tabular}{|c|c|c|}
\hline Specification & \multicolumn{2}{|c|}{ Value } \\
\hline Electrodes Diameter & \multicolumn{2}{|c|}{$8 \mathrm{~mm}$} \\
\hline Electrodes length & \multicolumn{2}{|c|}{$3 \mathrm{~cm}$} \\
\hline Electrolyte Height & \multicolumn{2}{|c|}{$4 \mathrm{~cm}$} \\
\hline Test tube & \multicolumn{2}{|c|}{1.5} \\
\hline Series Resistance & \multicolumn{2}{|c|}{$1 \mathrm{~K} \Omega$} \\
\hline Temp & \multicolumn{2}{|c|}{ Room Temperature } \\
\hline \multirow{4}{*}{ Time of Experiment } & $\mathrm{Cu}$-serum & 11:30 A.M \\
\hline & $\mathrm{Cu}$-water & 12:45 P.M. \\
\hline & GR-water & 12:15 P.M. \\
\hline & GR-serum & 12:45 P.M. \\
\hline Quantity of liquid & \multicolumn{2}{|c|}{5 to $10 \mathrm{ml}$} \\
\hline
\end{tabular}

\section{Results}

In the Table 2 the observation has been provided. As per the table we have applied different input voltage $V_{c c}$ is applied from 0 to 100 Volt range. Here $V_{r}$ is the voltage drop across the resistance $(1 \mathrm{~K})$ that has been connected in series of the circuit.

In the table as observed that after time to time the voltages across the series resistor is changed so up to the $120 \mathrm{sec}$ the observation has been provided at the $30 \mathrm{sec}$ interval. Here the meaning of the instant is at the time of the applied voltage.

In the respective column effect of the time delay for observations has been highlighted. The fact is that from input voltage range 0 volt to 1 volt the voltage across the resistor remains constant but from range 1 volt to 10 volt some amount of change has been noticed.

As per the ohm's law and voltage drop theory voltage drop across the liquid $V_{w}$ as given by

$$
V_{w}=V_{c c}-V_{r} \text { (instant) }
$$

Then current through the circuit is given by

$$
I=\frac{V_{r}}{R}
$$

Now with the help of the voltage drop across the liquid $\left(V_{w}\right)$ and current through the circuit (I) appropriate resistance has been calculated by ohm's law.

At last amount of percentage drop across the liquid has been indicated. The same observation has been taken for all four combinations. Refer Table 3, 4, 5.

Some Important Observation seen during the experiments:

1) CU-Water: Little reaction is get, compared to Serum, Bubbles at Cathode. Blue compound on Anode.

2) CU-serum:

More reaction was observed, compared to water having same electrode. Bubbles at Cathode. Blue compound on Anode.

3) GR-Water

Got bubbles on Anode first after $0.8 \mathrm{~V}$, and on Cathode on 5V.Bigger bubbles on Anode.

4) GR-Serum

Got bubbles on "Cathode" first after 3V, and on Anode after 6V. Bigger bubbles on Cathode. Too small at Anode

Comparison of VI characteristics for has been shown in Figure 2 for all four combinations

\section{Discuusion \& Conclusion}

For solid state electronics a resistor can easily express with three variables as per equation (2). It is not such simple with liquid electronics. Instead of one material dependent variable, in case of liquid there are number of parameter that can vary independently and change the resistivity of liquid. Again it is also depend on the methodology and electrode size, shape \& material. By this work we have started to derive one common parameter as per liquid characteristics so we can define a resistivity of liquid by a single equation. 
As per the general effects of physics even if temperature during experiment, atmospheric condition, Quantity of liquid, material of wire, dimensions of wire, schedule of experiment etc may effects the experiment output. With respect to such situation we have tried to take reading with above mentioned time and material combinations. By observing all table, it is easily understood that this completely a different case compare to solid one. The voltage fluctuation is comes in each reading. Again the result is not stable, where in case of solid it is robust fix. Even more, as time passed away the digital multi meter change its reading. That is why reading is also taken at various time intervals of seconds. The middle column indicates the voltages across liquid remain constant (almost). Based on this we can calculate the current passing through liquid. In same manner we can also find out the voltage drop in serum or water which is mention in percentage form. By doing this we can find resistivity of liquids.

It is clearly predictable, the considered all parameter effects the output results. In other words, all mentioned parameter are helpful to define resistivity of liquid. Additionally, percentage drop column saying that drop is increase directly with higher applied voltage. In same manner resistivity of liquid will decrease as the larger amount of supply voltage is given. The relation of voltage drop and resistivity is found as like as in case of solid. But new thing the liquid resistivity is vary with applied voltage which is completely opposite to solid material. A resistivity should not dependent on supplied voltages. In general convenience, especially in solid material a resistivity is independent of applied voltages. By finding such behavior, it becomes interesting to find out all characteristics of liquid (all the various types). Here we have represent with two liquid forms, so difficult to generalize the common equation form for all liquids like solid materials. But may next onwards may be in future work a electronics can be found made of liquid. At that time such unique equation will be the basic form, as right now equation (2) in case of solid material.

Table 2 Observations For $\mathrm{Cu}$-Water Combination

\begin{tabular}{|c|c|c|c|c|c|c|c|c|c|}
\hline \multicolumn{6}{|c|}{ Copper Electrodes with Tap-Water as Electrolyte } & Liquid Volts & Current & Resistance of Electrolyte & \% Voltage drop \\
\hline Vcc & $\mathrm{Vr}$ & $30 \mathrm{~s}$ & $60 \mathrm{~s}$ & $90 \mathrm{~s}$ & $120 \mathrm{~s}$ & $\mathrm{VW}$ & $\mathrm{I}(\mathrm{A})$ & Req(K.ohm) & $\%$ \\
\hline 2 & 0.108 & 0.123 & 0.132 & 0.139 & 0.137 & 1.892 & 0.000108 & 17.519 & 94.6 \\
\hline 4 & 0.371 & 0.318 & 0.299 & 0.295 & 0.3 & 3.629 & 0.000371 & 9.782 & 90.73 \\
\hline 5 & 0.462 & 0.46 & 0.469 & 0.474 & 0.47 & 4.538 & 0.000462 & 9.823 & 90.76 \\
\hline 6 & 0.643 & 0.643 & 0.64 & 0.64 & 0.662 & 5.357 & 0.000643 & 8.331 & 89.28 \\
\hline 9 & 0.981 & 0.934 & 0.92 & 0.91 & 0.911 & 8.019 & 0.000981 & 8.174 & 89.1 \\
\hline 10 & 1.02 & 1.01 & 0.99 & 0.984 & 1 & 8.98 & 0.00102 & 8.804 & 89.8 \\
\hline
\end{tabular}

Table 3 Observations For $\mathrm{Cu}-$ Serum Combination

\begin{tabular}{|c|c|c|c|c|c|c|c|c|c|}
\hline \multicolumn{6}{|c|}{ Copper Electrodes with Serum as Electrolyte } & \multirow{2}{*}{$\frac{\text { Liquid Volts }}{\mathrm{VW}_{\mathrm{W}}}$} & \multirow{2}{*}{$\begin{array}{c}\text { Current } \\
\mathrm{I}(\mathrm{A})\end{array}$} & \multirow{2}{*}{$\begin{array}{c}\text { Resistance of Electrolyte } \\
\text { Req(K.ohm) }\end{array}$} & \multirow{2}{*}{$\begin{array}{c}\% \text { Voltage drop } \\
\% \\
\end{array}$} \\
\hline Vec & $\mathrm{Vr}$ & $30 \mathrm{~s}$ & $60 \mathrm{~s}$ & $90 \mathrm{~s}$ & $120 \mathrm{~s}$ & & & & \\
\hline 1 & 0.084 & \multicolumn{4}{|c|}{ Same as Vr } & 0.916 & 0.000084 & 10.905 & 91.6 \\
\hline 2 & 0.35 & 0.291 & 0.24 & 0.202 & 0.178 & 1.65 & 0.00035 & 4.714 & 82.5 \\
\hline 3 & 0.695 & 0.726 & 0.715 & 0.765 & 0.784 & 2.305 & 0.000695 & 3.317 & 76.83 \\
\hline 4 & 1.24 & 1.3 & 1.59 & 1.57 & 1.56 & 2.76 & 0.00124 & 2.226 & 69 \\
\hline 5 & 2.06 & 2.23 & 2.43 & 2.44 & 2.43 & 2.94 & 0.00206 & 1.427 & 58.8 \\
\hline 6 & 3.19 & 3.25 & 3.2 & 3.25 & 3.32 & 2.81 & 0.00319 & 0.881 & 46.83 \\
\hline 7 & 3.66 & 3.88 & 3.86 & 3.85 & 4.03 & 3.34 & 0.00366 & 0.913 & 47.71 \\
\hline 8 & 4.82 & 4.84 & 4.88 & 4.91 & 4.95 & 3.18 & 0.00482 & 0.66 & 39.75 \\
\hline 9 & 5.65 & 6.06 & 6.06 & 6.06 & 6.06 & 3.35 & 0.00565 & 0.593 & 37.22 \\
\hline 10 & 6.96 & 6.95 & 6.95 & 6.95 & 6.95 & 3.04 & 0.00696 & 0.437 & 30.4 \\
\hline
\end{tabular}

Table 4 Observations For Gr-Water Combination

\begin{tabular}{|c|c|c|c|c|c|c|c|c|c|}
\hline \multicolumn{6}{|c|}{ Grafite Electrodes with Tap-Water as Electrolyte } & \multirow{2}{*}{$\frac{\text { Liquid Volts }}{\mathrm{VW}_{\mathrm{w}}}$} & \multirow{2}{*}{$\frac{\text { Current }}{\mathrm{I}(\mathrm{A})}$} & \multirow{2}{*}{$\begin{array}{c}\begin{array}{c}\text { Resistance of } \\
\text { Electrolyte }\end{array} \\
\text { Req(K.ohm }) \\
\end{array}$} & \multirow{2}{*}{$\begin{array}{c}\% \text { Voltage drop } \\
\%\end{array}$} \\
\hline Vcc & $\mathrm{Vr}$ & $30 \mathrm{~s}$ & $60 \mathrm{~s}$ & $90 \mathrm{~s}$ & $120 \mathrm{~s}$ & & & & \\
\hline 1 & 0.052 & 0.046 & 0.04 & 0.038 & 0.035 & 0.948 & 0.000052 & 18.231 & 94.8 \\
\hline 2 & 0.16 & 0.14 & 0.125 & 0.118 & 0.113 & 1.84 & 0.00016 & 11.5 & 92 \\
\hline 3 & 0.326 & 0.3 & 0.287 & 0.28 & 0.275 & 2.674 & 0.000326 & 8.202 & 89.13 \\
\hline 4 & 0.531 & 0.518 & 0.5 & 0.486 & 0.477 & 3.469 & 0.000531 & 6.533 & 86.73 \\
\hline 5 & 0.755 & 0.765 & 0.777 & 0.785 & 0.794 & 4.245 & 0.000755 & 5.623 & 84.9 \\
\hline 6 & 1.18 & 1.23 & 1.27 & 1.286 & 1.293 & 4.82 & 0.00118 & 4.085 & 80.33 \\
\hline 7 & 1.67 & 1.69 & 1.712 & 1.71 & 1.69 & 5.33 & 0.00167 & 3.192 & 76.14 \\
\hline 8 & 2.08 & 2.05 & 2.05 & 2.03 & 2.01 & 5.92 & 0.00208 & 2.846 & 74 \\
\hline 9 & 2.38 & 2.36 & 2.34 & 2.34 & 2.32 & 6.62 & 0.00238 & 2.782 & 73.56 \\
\hline 10 & 2.67 & 2.67 & 2.64 & 2.59 & 2.55 & 7.33 & 0.00267 & 2.745 & 73.3 \\
\hline
\end{tabular}


First Step towards Liquid State Electronics through Analysis of Liquid Resistivity in Water and ....

Table 5 Observations For Gr-Serum Combination

\begin{tabular}{|c|c|c|c|c|c|c|c|c|c|}
\hline \multicolumn{6}{|c|}{ Grafite Electrodes with Serum as Electrolyte } & \multirow{2}{*}{$\frac{\text { Liquid Volts }}{\mathrm{VW}_{\mathrm{w}}}$} & \multirow{2}{*}{$\begin{array}{c}\text { Current } \\
\mathrm{I}(\mathrm{A}) \\
\end{array}$} & \multirow{2}{*}{$\begin{array}{c}\begin{array}{c}\text { Resistance of } \\
\text { Electrolyte }\end{array} \\
\text { Req(K.ohm) }\end{array}$} & \multirow{2}{*}{$\begin{array}{c}\% \text { Voltage drop } \\
\% \\
\end{array}$} \\
\hline Vin & $\mathrm{Vr}$ & $30 \mathrm{~s}$ & $60 \mathrm{~s}$ & $90 \mathrm{~s}$ & $120 \mathrm{~s}$ & & & & \\
\hline 1 & 0.121 & 0.088 & 0.075 & 0.066 & 0.059 & 0.879 & 0.000121 & 7.264 & 87.9 \\
\hline 2 & 0.56 & 0.425 & 0.343 & 0.288 & 0.245 & 1.44 & 0.00056 & 2.571 & 72 \\
\hline 3 & 0.82 & 0.682 & 0.648 & 0.625 & 0.615 & 2.18 & 0.00082 & 2.659 & 72.67 \\
\hline 4 & 1.365 & 1.34 & 1.326 & 1.316 & 1.311 & 2.635 & 0.001365 & 1.93 & 65.88 \\
\hline 5 & 2.06 & 2.05 & 2.05 & 2.05 & 2.05 & 2.94 & 0.00206 & 1.427 & 58.8 \\
\hline 6 & 2.86 & 2.87 & 2.87 & 2.87 & 2.87 & 3.14 & 0.00286 & 1.098 & 52.33 \\
\hline 7 & 3.73 & 3.73 & 3.73 & 3.73 & 3.73 & 3.27 & 0.00373 & 0.877 & 46.71 \\
\hline 8 & 4.61 & 4.61 & 4.61 & 4.61 & 4.61 & 3.39 & 0.00461 & 0.735 & 42.38 \\
\hline 9 & 5.44 & 5.45 & 5.45 & 5.45 & 5.45 & 3.56 & 0.00544 & 0.654 & 39.56 \\
\hline 10 & 6.36 & 6.36 & 6.36 & 6.36 & 6.36 & 3.64 & 0.00636 & 0.572 & 36.4 \\
\hline
\end{tabular}

\section{Acknowledgement}

This research paper is made possible through the help and support from everyone, including: parents, teachers, family, friends, and in essence, all sentient beings. Especially, please allow me to dedicate my acknowledgment of gratitude toward all the significant advisors and contributors,

I would like to thank CHARUSAT faculties and staff for their support and encouragement. The product of this research paper would not be possible without all of them. Finally, I sincerely thank to my parents, family, and friends, who provide the advice and financial support.

\section{References}

[1]. Shiv Prasad Kosta, Manthan Manavadaria, Killol Pandya, Yogesh Prasad Kosta, Shakti Kosta, Harsh Mehta and Jaymin Patel, Human blood plasma-based electronic integrated circuit amplifier configuration, Journal of Biomedical Reseach, ISSN: 1674-8301,vol 27 issue 6, 2013, pp 520-522

[2]. Mitesh joshi, Manjul kumar, P.N. Gajjar, B.Y. Thakore,A.R. Jani, Electrical resistivity of liquid al-mg binary alloys Scientific journal advances materials research vol $625 \mathrm{Feb}, 2013$, pp 76-79

[3]. Schiefelbein, Naomi Fried, Kevin G. Rhoads, Donald R. Sadoway, A high-accuracy, calibration-free technique for measuring the electrical conductivity of liquids, Review of scientific instruments, Vol. 69/9, Sept.1998

[4]. Van Der Marel, Van oosten, Geertsma and W Van Der Lugtthe, Electrical resistivity of liquid lisn, nasn and na-pb alloys strong effects of chemical interactions, J. phys. Metal phys. 12,1982 , pp 49-61

[5]. Pankajsinh B. Thakor, J.J. Patel, Yogeshkumar, A.Sonvane, P.N. gajjar, A.R. jani, Electrical resistivity of ni-cr liquid binary alloy, Scientific journal solid state phenomena advances materials research vol 204,2014, pp 230-236

[6]. R Endo, S Maeda, Y Jinnai, M Kuwahara, Y Kobayashi and M Sua, Electric resistivities of liquid sb2te3 and ge2sb2te5, symposium E\PCOS, 2009

[7]. K hiratat, Y Wasedat, A Jaintlj and R Srivastavat, Resistivity of liquid transition metals and their alloys using the t matrix, J. phys. f: metal phys. vol. $7 / 3,1977$

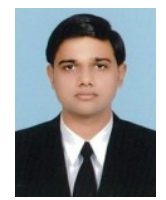

Manthan S. Manavadaria has obtained his M. Tech. degree in Communication Engineering field from CSPIT, CHARUSAT, Changa and B.E. in EC field from DDIT, DDU, Nadiad, Gujarat. He has done his master's dissertation project as NFP-Intern at ITER-INDIA, Gandhinagar, Gujarat in 2010-11. Currently he is pursuing his Doctorate Degree course in Bio-Electronics area from CSPIT, CHARUSAT, Changa, Gujarat, INDIA. His main interested areas are BioElectronics, Liquid State Electronics, RF \& Microwave and Networking. At present he is working as assistant professor at EC Department, CSPIT, CHARUSAT, Changa.

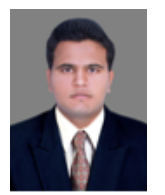

Vishal P. Tank has obtained his M. E. degree in Communication Engineering field from L.D. Engineering College, GTU and B.E. in EC field from DDIT, DDU, Nadiad, Gujarat. At present he is working as assistant professor at EC Department, CSPIT, CHARUSAT, Changa. He had worked as head of EC Department at Noble Engineering College, GTU, Junagadh in 2011-2012. His main interested areas are DSP and Networking.

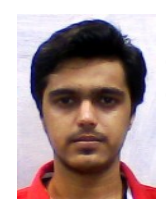

Currently, Shivansh dave is doing engineering graduation in Electronics and communication Field from EC Department, CSPIT, CHARUSAT, Changa.

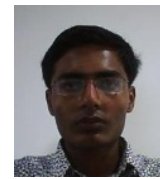

Currently, Paras Mangukiya is doing engineering graduation in Electronics and communication Field from EC Department, CSPIT, CHARUSAT, Changa. 